\title{
Prompt-Rich CMC on YouTube: To What or to Whom Do Comments Respond?
}

\author{
Susan C. Herring \\ Indiana University, Bloomington \\ herring@indiana.edu
}

\author{
Seung Woo Chae \\ Indiana University, Bloomington \\ seuchae@iu.edu
}

\begin{abstract}
Participants in textual CMC must identify to whom or what a message responds in order to establish conversational coherence. Media sharing sites provide rich prompts that make available multiple, diverse, potential addressees. We conducted an exploratory content analysis of addressee types and how they relate to the content of messages in three YouTube comment threads related to the COVID-19 pandemic, applying addressee and topic coding schemes inspired by [6]'s YouTube participation framework. Some addressee types and content types were mentioned significantly more frequently than others, although there was variation across threads. Also, certain kinds of topics were addressed more with certain addressees, and different topics were addressed in replies than in comments. Thus, the interaction between addressee and message content should be considered in analyses of conversational coherence on YouTube and other rich-prompt CMC platforms.
\end{abstract}

\section{Introduction}

An ideally coherent conversation consists of a sequence of initiating and responding turns [27] in which the latter are relevant to the former [9]. Based on this assumption of reply relevance, designers have created conversational CMC interfaces $[5,28]$ and researchers have analyzed and visualized sequential structures, topic development, and other conversational phenomena in CMC environments [10, 19]. In line with [9], some approaches are based on semantic or pragmatic relatedness between message contents $[5,11,13,21]$; these typically involve manual analysis. In contrast, automated approaches to the identification and visualization of conversation threads typically treat the message, a technological artifact, as a response to some prior message, with structural cohesive devices, such as use of the 'reply' function, constituting the relation or tie between

\footnotetext{
${ }^{1}$ Lüngen and Herzberg (2019) also distinguish three types of "reply relations" in CMC, two of which overlap with the 'message' ('technical') and 'content' ('interpretive') types in Figure 1. Their
}

the two messages [25, 30]. However, in neither approach has much attention been paid to the addressee, although it is generally assumed that when a message replies to a previous message or proposition, the sender is also replying to (addressing) the source of that message or proposition. These three types of response relations $^{1}$ are illustrated schematically in Figure 1.

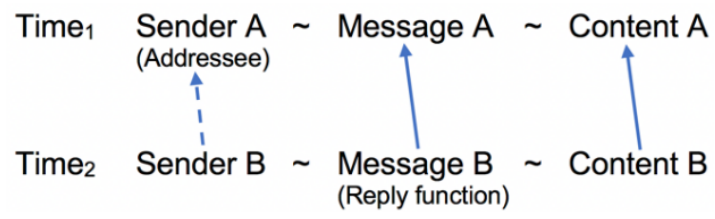

Figure 1. Three response relations

(Vertical arrow means "responds to")

In automated conversation thread identification, the three relations in Figure 1 are implicitly assumed to be in alignment. However, there are a number of problems with this assumption. First, Sender A is not always the intended addressee. A message can formally respond to a prior message using the same subject header but indicate explicitly or implicitly that the intended addressee is someone else, e.g., a third party who is interested in the exchange between A and B. Second, subject headers do not always correspond to message content. A responder might use the reply function but change the topic, or they might respond on the same topic using a modified or new subject header [24]. Finally, not all CMC platforms provide a reply function, as with most synchronous chat. On such platforms, user practices such as addressivity (invoking the intended addressee's name or userID) [31] can provide clues to message relatedness. However, knowing to whom a message is addressed does not indicate what the message is about or how it relates to the content of the previous message, and thus by itself it does not establish relevance. (This is indicated by the dotted arrow in Figure 1.) Relevance must also be inferred from message content and context,

third type is user-initiated indentation, e.g., on Wikipedia Talk pages; this would be considered a user-generated variant of the 'message' relation in the present study. 
which can be challenging in multi-participant CMC in which topical threads are often interleaved $[10,28]$.

Moreover, CMC has evolved over the years in important ways that affect response patterns. First, fewer platforms offer 'deep' threading with indentation for each level of reply, as was the case for many early online discussion forums. It is more common now on platforms such as Facebook and YouTube for a single level of indentation to be used for replies to comments, effectively creating a 'shallow' binary structural distinction between comments (responses to a prompt) and replies (responses to comments). This makes the reply function a less reliable indicator of addressee. 'Shallow' threading mechanisms actually obscure the intended addressee of a reply-to-a-reply by positioning it at the end of a sequence, rather than adjacent to the reply it responds to.

Second, rather than proceeding in a step-wise fashion through commenter interaction, as was common in earlier modes of CMC such as IRC and email lists, conversations on current social media platforms tend to be prompt focused [12]. That is, comments tend to respond more to initial prompts (posts on Facebook and Twitter; news stories; videos, etc.) than to other comments, suggesting that prompts are a new kind of addressee.

Relatedly, media-sharing platforms such as YouTube offer multifaceted prompts that incorporate a diversity of possible addressees [6], including the person who posted the video, the video itself, and speakers in the video. We refer to these as prompt-rich platforms. Formal mechanisms to specify the intended addressee on such platforms are lacking, however. The 'reply' function can only be used to respond to a previous commenter. A more flexible indicator of addressivity is the @ sign [14]; however, this mechanism by itself does not differentiate among different kinds of addressees.

We posit that the addressee relation type in Figure 1 (Sender B responds to Sender A) is crucial to understanding response relevance on prompt-rich platforms like YouTube, and that it is not simply equivalent to the message-responds-to-message relation. To investigate this proposition, we conducted an exploratory analysis of addressee types and how they relate to the content of messages in YouTube comment threads. Specifically, we ask: Of the potential addressees available for a given YouTube video, which ones are addressed most often by commenters, and how does the topic of the message vary according to the entity to which it responds?

Using content analysis methods, we developed multifaceted addressee and topic coding schemes inspired by [6]'s YouTube participation framework. The schemes were applied to comments posted below three YouTube videos that were selected to represent a variety of different possible addressees, and that were posted around the time when shelter-in-place orders due to the COVID-19 pandemic went into effect in the United
States in spring 2020. Some addressee types (e.g., general audience, matrix speaker in the video, previous commenter) and content types (e.g., the matrix speaker, the speaker's content, and the general situation, including COVID-19 and President Trump) were mentioned significantly more frequently than others, although there was variation across the comment threads. Moreover, topic and addressee were found to interact, such that certain kinds of topics were addressed more with certain categories of addressee, and different topics were addressed in replies (addressing previous commenters) than in comments (addressing other addressees). Based on these findings, we argue that the interaction of addressee and message content needs to be considered in analyses of conversational coherence in comment threads on YouTube and other rich-prompt CMC platforms. We conclude by considering the implications of our findings for the design of such platforms and CMC analysis tools, as well as for research on conversational coherence in rich-prompt platforms more generally.

\section{Relevant Research}

\subsection{Addressee analysis}

The addressee is one to whom something is addressed; in conversation, it is the intended hearer or receiver of a message. Analysts of, and participants in, textual CMC must identify to whom or what a message responds in order to establish conversational coherence. This can be challenging in multi-participant textual conversations with interleaved threads and disrupted turn adjacency [10]; therefore, different means have developed to fill this function. Use of a technical reply function, when available, points to the intended addressee in many cases, albeit not all, as noted in Section 1. Nontechnical means of addressee identification such as addressivity [31], with or without the @ sign, provide pointers to previous contributors, especially in chat environments. In asynchronous environments, quoted parts of a previous message often include identifying information about the quoted person who is being addressed [26]. To this list can be added cohesive linguistic devices that allow inferences to be drawn about to what or whom a message is responding, such as question-answer sequences [20], successive greetings, acknowledgments, and semantic coreference [21].

In traditional $\mathrm{CMC}$ environments such as in chat rooms and forums, addressees are participants or potential participants. However, on sites where participants mostly respond to a multimedia prompt, the prompt itself can be considered an addressee. Prompts as addressees raise a special set of issues. For example, the roles of addressee and sender are normally not fixed; an individual can be an addressee in one exchange and a sender 
in the next [6]. When a prompt is addressed, however, it is one-way communication, in that the prompt is not expected to, and usually does not, respond back. (The exception is when the person who posted the prompt participates in the comment thread). In this regard, addressing comments to multimedia prompts is similar to posting text comments to television shows [15].

Moreover, prompts such as news stories, videos, images, and GIFs on media-sharing sites make available multiple, diverse potential addressees. In the case of a video prompt on YouTube, the potential addressees include the producer of the video, the person who posted it, and the people (actors) who appear in it, as well as the YouTube platform itself. There is a hierarchical relation among these addressees, in that some are embedded in others [6]. Finally, the prompt as a whole can initiate a conversational thread if commenters respond to it, as they often do [12]. This raises the question of whether such prompts should be treated as turns in interaction [2], and if so, how they should be represented in analyses of computer-mediated conversation.

\subsection{Thread/topic analysis}

Thread and topic analyses aim to identify the structure and overall coherence of extended exchange sequences. As in addressee analysis, "annotating reply relations constitutes a prerequisite for correctly identifying relational structures between user contributions" [20].

Such relations have been identified automatically in studies that create a visual interface to display patterns for analysis or to improve communication among users. For example, [19] visualized contributor interactions on Wikipedia Talk pages, and [25, 30] designed thread visualizations to reduce complexity and provide context in email clients. Further, [28] created a threaded chat system that let users create structural ties between messages based on the position of messages in the interface. In these interface designs, addressees are assumed to be the sender of the message to which the reply responds.

In other approaches, such as Dynamic Topic Analysis (DTA) [11, 12], relations are identified manually based on semantic and pragmatic relatedness between topical propositions, and tree structures are generated to visualize topic flow [VisualDTA, 13]. In DTA, addressees are associated with their propositions, rather than their messages, if they are relevant to the analysis at all.

Similarly, in an earlier study, [21] analyzed both threads and topics in a comparison of face-to-face and CMC conversations among astrophysicists. The researchers manually constructed threads by relating portions of messages to previous contributions based on linguistic cues. Also, each conversational turn was coded according to five content categories: science, technol- ogy, display coordination, session coordination, and socializing. Like DTA, [21]'s approach decouples message and addressee, and in that respect foreshadows the present study. However, their analysis did not relate the threads to the topics that were discussed.

Over a period of years, use of the VisualDTA tool [13] revealed a change in typical CMC interaction patterns, from stepwise topic progression (or decay [17]) to a more prompt-focused structure on social media platforms [12]. This observation lays part of the foundation for the present study, which has at its core the question of how to analyze the prompt itself. The other part of the foundation is research on the YouTube platform.

\subsection{YouTube}

YouTube is the second most popular social media platform, with more than two billion users [23]. Early research focused on the platform as a new mass media outlet [29], as well as on video sharing by individuals [18]. More recently, a number of researchers have become interested in how the platform is used by microcelebrities (YouTubers) who lead discussion about current events, such as the 2015 Finnish refugee crisis [16]. Communication on YouTube has also been studied in the context of mass shootings, natural disasters, and epidemics, including the Ebola virus $[1,22]$.

Another relevant YouTube research trajectory is the linguistic study of interaction management in comment threads. In contrast to [12]'s description of YouTube as a prompt-focused Web 2.0 platform, [3] focused on commenter interaction in YouTube comment threads on hotly-debated topics. In [3]'s analysis of turn relatedness, considerable adjacency was found between comments, and the authors concluded that "polylogues are sufficiently connected so as to constitute a space for online interaction" [3]. Relatedly, [2] questioned the position of the YouTube video in the interactional scheme of the comment threads. Specifically, he asked whether a comment can be treated as interactional even if it responds only to the video and not to any other comment.

This question is partially addressed by [6], who proposed a dimensional framework for overall communication on YouTube. The framework comprises three levels in which different types of interaction are available. The first level is communication between speaker(s) and hearers in the video. The second is communication between video senders and recipients ('hearers'). In this level, the hearers can address the senders and potentially interact with them by commenting on the video. The third level is interaction in the YouTube comment threads among the video recipients, who alternately take on the role of speaker and hearer. However, [6]'s framework does not entirely address Benson's question, in that it recognizes interaction between commenters and 
video senders, but not between commenters and the video itself (or its contents). Nor does the framework consider topics. Moreover, [6]'s contribution is conceptual; she does not apply her framework to data analysis.

The current study empirically analyzes both addressees and topics in YouTube comment threads, as well as the relationship between them. Our focus is on [6]'s second and third levels (user comments); moreover, expanding [6]'s study, we consider additional possible addressees and assume that any addressee can also be the topic of a YouTube comment.

Specifically, we address two research questions:

RQ1: Of the potential addressees in the YouTube videos and comments, which are addressed most often by commenters?

RQ2: How, if at all, do topics in YouTube comment threads vary according to their addressees?

\section{Methods}

\subsection{Data}

In March 2020, citizens in parts of the U.S. were told to "shelter in place" to limit the spread of the COVID-19 virus. In response, some people started hoarding supplies, resulting in shortages of toilet paper and other essential items. Television personalities began broadcasting from their basements, attics, and other parts of their homes. Meanwhile, many people were becoming infected with the virus, especially in the New York City area. The three YouTube videos whose comment threads were analyzed in this study represent each of those situations, as described in Table 1.
The three videos were selected to include as many potential addressees as possible, where 'addressee' was initially broadly defined to encompass persons, entities, and types of content - anything that commenters could "address" in their comments. (This definition was subsequently narrowed.) The types of matrix speaker vary (a famous comedian, a famous news commentator, a YouTube personality). The videos were produced by different entities (television station in collaboration with matrix speaker; television station; YouTuber), and they include different amounts and types of embedded video. The Chris Cuomo Show video was also redistributed (as a video recording of a television program) by a third party, who constitutes another potential addressee. ${ }^{2}$ The videos have in common that they all responded to the COVID-19 pandemic, were broadcast from the matrix speaker's home in the last two weeks of March, and had attracted at least 500 comments as of April 8, 2020, when we collected the threads.

The first (oldest) 500 comments were collected from each thread through the YouTube API using Python 3.7.1. We also captured screen shots of the threads to preserve emoji and other visual icons. The sample that was analyzed for this paper consists of the first 200 comments (including replies) from each thread. This number was considered sufficient to capture all common commenting behaviors, since YouTube comment threads tend to be repetitive. The earliest comments were collected, so as to include in the sample the context for replies to earlier comments. Because the comments and replies were typically short, most of them contained a single main idea. When a message included more than one main idea, it was divided into separate topical propositions, following the Dynamic Topic Analysis (DTA)

Table 1. Description of the video prompts

\begin{tabular}{|l|l|l|l|l|}
\hline $\begin{array}{l}\text { YouTube } \\
\text { Channel }\end{array}$ & Matrix Video & $\begin{array}{l}\text { Date } \\
\text { Posted }\end{array}$ & Description & Embedded Video \\
\hline $\begin{array}{l}\text { The Late } \\
\text { Show with } \\
\text { Stephen } \\
\text { Colbert }\end{array}$ & $\begin{array}{l}\text { The Big Story Tonight Is } \\
\text { Yistancing" Edition of } \\
\text { The Late Show }\end{array}$ & $\begin{array}{l}\text { March 17, } \\
2020\end{array}$ & $\begin{array}{l}\text { Comedian Stephen Colbert } \\
\text { "social distances" by } \\
\text { broadcasting his nightly } \\
\text { monologue from his bathtub }\end{array}$ & $\begin{array}{l}\text { Brief clip of President Trump } \\
\text { speaking at a press conference }\end{array}$ \\
\hline $\begin{array}{l}\text { (reposted } \\
\text { from CNN) }\end{array}$ & Chris Cuomo Show & $\begin{array}{l}\text { March 31, } \\
2020\end{array}$ & $\begin{array}{l}\text { Chris Cuomo, broadcasting his } \\
\text { news show from his basement, } \\
\text { announces that he has covid-19 }\end{array}$ & $\begin{array}{l}\text { Andrew Cuomo, speaking at a } \\
\text { press conference }\end{array}$ \\
\hline TBTV & $\begin{array}{l}\text { Shopper Proves Bernie's } \\
\text { Point }\end{array}$ & $\begin{array}{l}\text { March 22, } \\
2020\end{array}$ & $\begin{array}{l}\text { YouTube personality Tim } \\
\text { Black shares videos and } \\
\text { advocates for US presidential } \\
\text { candidate Bernie Sanders }\end{array}$ & $\begin{array}{l}\text { Amateur video of a woman } \\
\text { prearding toilet paper; clip of } \\
\text { prential candidate Joe Biden } \\
\text { speaking at a campaign rally }\end{array}$ \\
\hline
\end{tabular}

${ }^{2}$ Shortly after we collected our data sample, the Cuomo video and
comment thread were removed from YouTube. 
approach [11]. Thus, the total number of propositions is greater than 200 for each thread. Table 2 displays descriptive metrics for the three comment threads.

Table 2. Comment thread metrics (raw numbers)

\begin{tabular}{lllll}
\hline Thread & $\begin{array}{l}\text { Total } \\
\text { Comments }\end{array}$ & $\begin{array}{l}\text { Sample } \\
\text { Comments }\end{array}$ & $\begin{array}{l}\text { Sample } \\
\text { Propositions }\end{array}$ & $\begin{array}{l}\text { Sample } \\
\text { Words }\end{array}$ \\
\hline Colbert & 6,870 & 200 & 210 & 2,280 \\
Cuomo & 729 & 200 & 240 & 3,156 \\
Black & 589 & 200 & 223 & 4,634 \\
\hline Total & 8,188 & 600 & 673 & 10,070 \\
\hline
\end{tabular}

Note: "Comments" include both comments and replies to comments.

\subsection{Analysis methods}

Content analysis was used to categorize and analyze the frequency of occurrence of each type of addressee and topic, as well as the relationship between the two types. The unit of analysis was the topical proposition. In an iterative process, we created two separate coding schemes (Appendix, Tables A and B), inspired by [6], with a focus on comments in threads. Building on and modifying [6]'s participation framework, we distinguished between addressees and topics, and added other possible entities in each category based on our prior knowledge of YouTube comment threads (e.g., the situation of the matrix video; persons in embedded videos, etc.). In this process, the notion of 'addressee' was narrowed to include only persons or entities directly addressed by a commenter, as accomplished, e.g., through use of the reply function or the @ sign; through linguistic means such as vocatives, second person pronouns, and imperative verb forms; or through formulaic expressions such as greetings, thanks, and well-wishes.

'Topic' was operationalized as the main content or ideational proposition referred to in a comment or reply. The topic categories were partially derived from the addressee categories, with the remaining categories emerging from the data. The resulting categories were grouped into seven broad topic categories, with the codes numbered accordingly: 1. Situation, 2. Setting, 3. Speaker's Content, 4. Producer's message, 5. Video, 6. People, and 7. Other (including matrix channel or show, the YouTube platform, previous self-comment, etc.). ${ }^{3}$ The addressee and topic codebooks are presented, with examples from our full dataset, in Tables A and B in the Appendix. Addressee code numbers are preceded by the letter 'A' and topic code numbers by the letter 'T.'

To determine interrater reliability, both authors coded 194 propositions, or $28.8 \%$ of the total 673 propositions. These were coded separately for addressees and topics for each of the three comment threads. While

\footnotetext{
${ }^{3}$ The exception to this numbering system is code T5-0, which was
} added later during the interrater assessment process. the result from the comment thread under the Cuomo video reached $80 \%$ agreement in the first round, the other two threads required an additional round. In the process, some of our code operationalizations were refined. The final agreements for each video featuring Colbert, Cuomo, and Black were 90.0\%, 86.8\%, and $80.0 \%$ for addressees $(\alpha=.801)$ and $80.0 \%, 88.7 \%$, and $85.0 \%$ for topics $(\alpha=.834)$, respectively. Consensus was reached on most of the coding disagreements after further discussion. The remaining data were then divided evenly and coded independently by each author. After coding, as an additional check, any remaining unclear propositions were resolved through discussion.

Results are presented first for addressees and topics separately, then combined, using descriptive statistics. Chi-square tests were conducted in R. In addition, a simple path diagram was created to visualize the relationship between addressees and topics.

\section{Results}

\subsection{Addressees}

Most messages were addressed to no one in particular, that is to say, to a general audience (A8). [6] refers to these as "free-floating commentaries." The next most common addressee was the matrix speaker in the video (A2-1), followed by previous commenters (A6). See Table 3 . Some addressee types from Table $A$ in the Appendix were not addressed in the comments in our data (e.g., A3, A4), and two others occurred rarely (A3-1, A5). The addressees varied significantly across threads, as confirmed by a Chi-square test for the most frequent five codes $\left(\mathrm{X}^{2}=154.59, \mathrm{df}=8, \mathrm{p}<.001\right)$.

Table 3. Frequencies of addressee codes

\begin{tabular}{llll}
\hline Code & $\begin{array}{c}\text { Colbert } \\
(\mathrm{n}=210)\end{array}$ & $\begin{array}{l}\text { Cuomo } \\
(\mathrm{n}=240)\end{array}$ & $\begin{array}{l}\text { Black } \\
(\mathrm{n}=223)\end{array}$ \\
\hline $\begin{array}{c}\mathrm{A} 8 \\
\mathbf{n}=\mathbf{2 6 1} ; \mathbf{3 8 . 8} \%\end{array}$ & $50.0 \%$ & $21.7 \%$ & $46.6 \%$ \\
$\begin{array}{c}\mathrm{A} 2-1 \\
\mathbf{n}=\mathbf{1 9 5} ; \mathbf{2 9 . 0} \%\end{array}$ & $27.1 \%$ & $50.4 \%$ & $7.6 \%$ \\
$\begin{array}{c}\mathrm{A} 6 \\
\mathbf{n}=\mathbf{1 6 7} ; \mathbf{2 4 . 8} \%\end{array}$ & $12.4 \%$ & $23.3 \%$ & $38.1 \%$ \\
$\begin{array}{c}\mathrm{A} 9 \\
\mathbf{n}=\mathbf{3 0} ; \mathbf{4 . 5} \%\end{array}$ & $8.6 \%$ & $3.8 \%$ & $1.3 \%$ \\
$\begin{array}{c}\mathrm{A} 1 \\
\mathbf{n}=\mathbf{1 6} ; \mathbf{2 . 4 \%}\end{array}$ & $1.9 \%$ & $0.4 \%$ & $4.9 \%$ \\
$\begin{array}{c}\text { Others* } \\
\mathbf{n}=\mathbf{4} ; \mathbf{0 . 6} \%\end{array}$ & $0.0 \%$ & $0.4 \%$ & $1.4 \%$ \\
\hline $\begin{array}{l}\text { All } \\
\mathbf{n}=\mathbf{6 7 3} ; \mathbf{1 0 0 . 0} \%\end{array}$ & $100.0 \%$ & $100.0 \%$ & $100.0 \%$ \\
\hline \% Others include all addressee codes with fewer than 10 occurrences
\end{tabular}




\subsection{Topics}

The most-mentioned topics in all three threads were those introduced by previous commenters (T5-0). These are broken down into subtopics in section 4.4. The next most frequent topic was the matrix speaker himself (T62-1) - his personality, appearance, etc. - followed by what the matrix speaker said in the video (T3-1). Other topics mentioned somewhat often include the broader situation (e.g., the COVID-19 pandemic; President Trump's response to it; US politics in general) (T1-1) and the physical setting of the speaker in the matrix video (T2-1). The latter was especially salient for Colbert and Cuomo, who were broadcasting from their homes for the first time due to the pandemic. Greetings and well-wishes were also common (T7-4), but only in comments on the Cuomo video. See Table 4. Not all the topic types in Table B were mentioned in our data (i.e., T4-2); others occurred rarely, e.g., T3-2, T2-2, T6-1, T7-2) and two others (T6-2-2 and T6-4) were not applicable to our data. The topics that commenters were more

Table 4. Frequencies of topic codes

\begin{tabular}{|c|c|c|c|}
\hline Code & $\begin{array}{l}\text { Colbert } \\
(\mathrm{n}=210)\end{array}$ & $\begin{array}{l}\text { Cuomo } \\
(\mathrm{n}=240)\end{array}$ & $\begin{array}{l}\text { Black } \\
(\mathrm{n}=223)\end{array}$ \\
\hline $\begin{array}{l}\mathrm{T} 5-0 \\
\mathbf{n}=\mathbf{1 2 7} ; \mathbf{1 8 . 9 \%}\end{array}$ & $9.5 \%$ & $14.2 \%$ & $32.7 \%$ \\
\hline $\begin{array}{l}\text { T6-2-1 } \\
n=95 ; \mathbf{1 4 . 1 \%}\end{array}$ & $23.3 \%$ & $17.5 \%$ & $1.8 \%$ \\
\hline $\begin{array}{l}\mathrm{T} 3-1 \\
\mathbf{n}=\mathbf{7 4} ; \mathbf{1 1 . 0} \%\end{array}$ & $10.5 \%$ & $14.6 \%$ & $7.6 \%$ \\
\hline $\begin{array}{l}\mathrm{T} 7-4 \\
\mathbf{n}=\mathbf{5 7} ; \mathbf{8 . 5 \%}\end{array}$ & $1.4 \%$ & $21.7 \%$ & $0.9 \%$ \\
\hline $\begin{array}{l}\mathrm{T} 1-1 \\
\mathbf{n}=\mathbf{5 3} ; \mathbf{7 . 9 \%}\end{array}$ & $8.1 \%$ & $3.8 \%$ & $12.1 \%$ \\
\hline $\begin{array}{l}\mathrm{T} 2-1 \\
\mathbf{n}=\mathbf{4 5} ; \mathbf{6 . 7 \%}\end{array}$ & $16.2 \%$ & $4.2 \%$ & $0.4 \%$ \\
\hline $\mathrm{T} 5-1$ & & & \\
\hline $\begin{array}{l}\mathbf{n}=\mathbf{2 9} ; \mathbf{4 . 3 \%} \\
\mathrm{T} 6-3-1\end{array}$ & $10.5 \%$ & $0.4 \%$ & $2.7 \%$ \\
\hline$n=29 ; 4.3 \%$ & $0.5 \%$ & $1.3 \%$ & $11.2 \%$ \\
\hline $\mathrm{T} 1-2$ & & & \\
\hline$n=25 ; 3.7 \%$ & $0.0 \%$ & $0.0 \%$ & $11.2 \%$ \\
\hline $\mathrm{T} 7-1$ & & & \\
\hline$n=23 ; 3.4 \%$ & $5.7 \%$ & $2.5 \%$ & $2.2 \%$ \\
\hline T6-6 & & & \\
\hline$n=22 ; 3.3 \%$ & $0.5 \%$ & $6.7 \%$ & $2.2 \%$ \\
\hline $\mathrm{T} 7-5$ & & & \\
\hline$n=21 ; 3.1 \%$ & $6.7 \%$ & $2.1 \%$ & $0.9 \%$ \\
\hline Others* & & & \\
\hline $\mathrm{n}=73 ; 10.9 \%$ & $7.1 \%$ & $11.3 \%$ & $13.9 \%$ \\
\hline All & & & \\
\hline$n=673 ; 100.0 \%$ & $100.0 \%$ & $100.0 \%$ & $100.0 \%$ \\
\hline
\end{tabular}

* Others include all topic codes with fewer than 20 occurrences.
Table 5. Topics used with each addressee

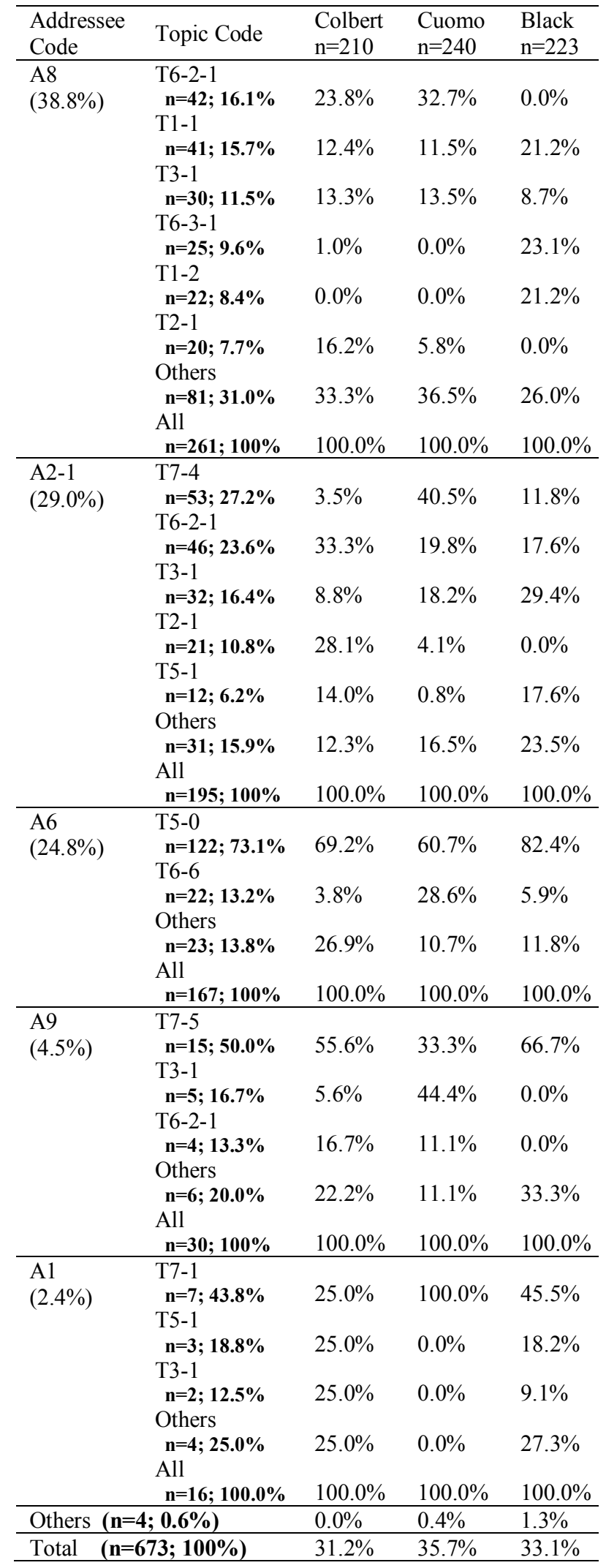


likely to mention varied significantly with the comment thread. The variance was statically supported by a Chisquare test for the most frequent 10 codes $\left(\mathrm{X}^{2}=328.98\right.$, $\mathrm{df}=18, \mathrm{p}<.001)$.

\subsection{Addressees and topics}

The previous sections show that the distribution of addressees and topics is not random; rather, some addressees and topics were strongly preferred in the threads. When topics are grouped by addressee type, furthermore, it becomes apparent that these preferences are interrelated, as shown in Table 5. Thus, when the matrix speaker in the video (A2-1) was directly addressed, the most common topics were greetings and well-wishes (T7-4), the speaker himself (T6-2-1), and what the speaker said (T3-1). The most common topic when the video producer (A1) was addressed was the show (T7-1), followed by the video (T5-1). When a previous commenter was addressed, regardless of whether the 'reply' function was used (A6), commenters overwhelmingly preserved the topic of that commenter (T5$0)$, except when they commented (usually unfavorably) on the commenter him- or herself (T6-6). When the addressee was ambiguous (A9), the topic was most often coded as unclear (T7-5).

When no one in particular was addressed (A8), various topics were mentioned roughly equally often, including the matrix speaker (T6-2-1), the broader situation (T1-1), and what the matrix speaker said (T3-1). In the Black video, commenters also often mentioned a woman in an embedded video who was buying up all the toilet paper at a store (T6-3-1) and the situation (toilet paper hoarding) that was illustrated in the video (T1-2).

\subsection{Topic code 5-0 and other topics}

Topic code 5-0 (previous commenter's content) is in fact a meta topic code that can be broken down further to show the specific topics that were referenced. The most frequently referenced topic in replies to comments was the general situation (T1-1), followed by what the matrix speaker said (T3-1). Also mentioned often was the woman in the embedded video who was hoarding toilet paper (T6-3-1), but only in replies to comments on Black's video. Conversely, the replies to comments on Black's video never mentioned the matrix speaker, although on the other two videos they did (T6-2-1 overall). Because the expected values are less than five in some threads for some categories, the breakdown across threads is not amenable to analysis using Chi squares.

We can, however, compare topic preferences in replies to comments with topic preferences in comments to other addressees, because the topics in each case are drawn from the same set (Table B). Moreover, code T5-
0 is nearly congruent with code A6: Almost all T5-0's were addressed to A6, and most (73.1\%) A6's were T50 's. Taking T5-0 as a proxy for A6, we compared the top five topic codes mentioned in replies with the same codes mentioned in comments to all other addressees except A6 (Table 6). Notably, the general situation is referenced more than twice as often in replies as in comments to other addressees, and the matrix speaker in the video is referenced more than three times as often in comments as in replies. A Chi-square test confirmed that the differences between the two columns in Table 6 are statistically significant $\left(\mathrm{X}^{2}=33.43, \mathrm{df}=4, \mathrm{p}<.001\right)$.

Table 6. Topics in replies vs. in other comments

\begin{tabular}{lll}
\hline & T5-0 & $\begin{array}{l}\text { All other addressees } \\
\text { except A6 }\end{array}$ \\
\hline T1-1 & $39(38.6 \%)$ & $47(16.8 \%)$ \\
T3-1 & $24(23.8 \%)$ & $69(24.6 \%)$ \\
T6-3-1 & $16(15.8 \%)$ & $28(10.0 \%)$ \\
T2-1 & $12(11.9 \%)$ & $43(15.4 \%)$ \\
T6-2-1 & $10(9.9 \%)$ & $93(33.2 \%)$ \\
\hline All & $101(100.0 \%)$ & $280(100.0 \%)$ \\
\hline
\end{tabular}

We also tested the differences in topic distribution between $\mathrm{T} 5-0$ and the two most frequent addressee codes, A8 (general audience) and A2-1 (matrix speaker). Again, the distributions of the most frequent five codes in T5-0 were compared. See Table 7. The same overall trends are evident as in Table 6 , but A8 differs from A2-1. Notably, comments addressed to the general audience were evenly split between the speaker in the video and the general situation, whereas comments addressed to the speaker in the video were mostly about the speaker himself, followed by the content of what he said. These differences were also statistically confirmed $\left(\mathrm{X}^{2}=66.68, \mathrm{df}=8, \mathrm{p}<.001\right)$

Table 7. Topics in replies vs. in comments to the two most frequent other addressees

\begin{tabular}{llll}
\hline & T5-0 & A8 & A2-1 \\
\hline T1-1 & $39(38.6 \%)$ & $41(25.9 \%)$ & $5(4.7 \%)$ \\
T3-1 & $24(23.8 \%)$ & $30(19.0 \%)$ & $32(30.2 \%)$ \\
T6-3-1 & $16(15.8 \%)$ & $25(15.8 \%)$ & $2(1.9 \%)$ \\
T2-1 & $12(11.9 \%)$ & $20(12.7 \%)$ & $21(19.8 \%)$ \\
T6-2-1 & $10(9.9 \%)$ & $42(26.6 \%)$ & $46(43.4 \%)$ \\
\hline All & $101(100.0 \%)$ & $158(100.0 \%)$ & $106(100.0 \%)$ \\
\hline
\end{tabular}

\subsection{Summary of sections 4.3 and 4.4}

The path diagram in Figure 2 shows the main associations discussed above between addressee and topic, and between T5-0 and its subtopics. The items in the 
columns are ordered in descending frequency of occurrence in the data. Line weights indicate the rank of the top three topic associations for each addressee (heaviest line $=$ strongest association); the association had to occur at least five times to be represented in the diagram. Each addressee (including T5-0) has a different line color.

From the diagram it can be seen that the matrix speaker's words (T3-1) are discussed often with four types of addressees: the matrix speaker (A2-1), the general audience (A8), an ambiguous addressee (A9), and in replies to comments (T5-0). The general situation (T1-1) is discussed most in replies (both related to a previous commenter's content, T5-0, and unrelated, A6) and in comments to the general audience (A8). The matrix speaker himself (T6-2-1) is also a frequent topic of comments addressed directly to him (A2-1), as well as to the audience at large (A8). In addition to these multiple associations, five out of the 12 top topics in Figure 2 are primarily associated with a single addressee type.

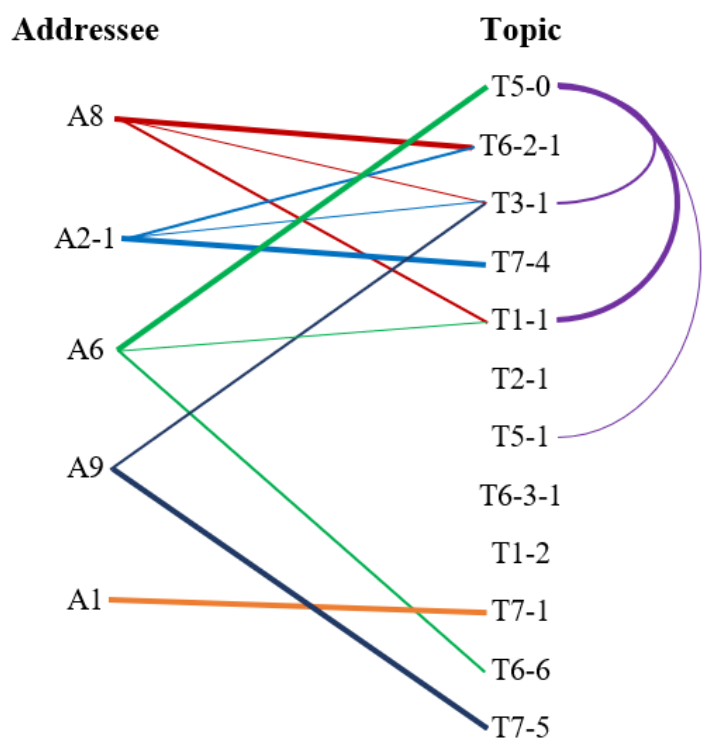

Figure 2. Associations between addressees and topics

\section{Discussion}

\subsection{Research questions revisited}

RQ1 asked, "Of the potential addressees in the YouTube videos and comments, which ones are addressed most often by commenters?" Comments specifically addressed to someone most often addressed the matrix speaker in the video and previous commenters. The frequency of the latter indicates a fairly high degree of interactivity in the threads, consistent with the findings of [3]. At the same time, the frequency of comments addressed to the matrix speaker is consistent with a prompt-focused pattern, as described by [12]. Finally, the high numbers of comments addressed to some aspect of the prompt suggest that the prompt is an integral part of the interaction on YouTube [cf. 2], even though the prompt does not respond. Yet, 39\% of comments were not addressed to anyone in particular (Table 3). This suggests that many commenters see YouTube as more of a declamatory stage [8] than as a conversation space.

Addressees varied across threads, with the Black thread differing from the other two in having both more replies to other commenters (perhaps due to the political themes in the video - YouTube commenters interact more on controversial topics [3]) and fewer comments addressed to Black himself. While Black is a microcelebrity on YouTube [16], the other threads were more focused on the mainstream celebrities in the videos.

Although it was not one of our research questions, the distribution of topics was also interesting (Table 4). The fact that most of the comments were about the person in the video and what he said shows that the threads were quite coherent and not highly divergent topically [cf. 17]. The commenters digressed most often when talking about the general situation: COVID-19, Trump's response to it, the upcoming US presidential elections.

RQ2 asked, "How, if at all, do topics in YouTube comment threads vary according to their addressees?" Addressees tended to specialize for certain kinds of content (Figure 2). This suggests that the addressee is an integral part of the message content, rather than independent of it (as suggested by Figure 1) or a proxy for the structural message. Thus, addressee should be taken into account in analyzing YouTube comment threads.

An additional finding that emerged from our analysis is that topics tended to differ in comments and replies to comments. In replies, commenters digressed more, talking about the general situation and their personal situation during the pandemic. In comments, they talked more about the people in the videos. Even though both comments and replies were public, replies were treated by commenters as "publicly private" [18] or in [8]'s theatrical metaphor, as back stage relative to comments, which occupy the front stage. The relationship is similar to that between Wikipedia Articles and Talk pages [19].

\subsection{COVID-19-related discussion}

People's emotional and psychological states during crisis events are reflected in their CMC [4]. The discussions in the YouTube threads during the early stages of the COVID-19 pandemic show that commenters used YouTube to cope with the crisis in different ways through humor (Colbert); sharing information about possible treatments (Cuomo); and critique of politicians' handling of the pandemic (Black). In comparison, [1] found little mention of treatment in YouTube videos about the Ebola pandemic. However, [22] identified 
criticism of politicians in YouTube discussions of Hurricane Sandy, along with talk about religion. Talk about natural disasters and events of short duration can be expected to differ from talk about pandemics, which last longer and may involve more future uncertainty.

\section{Conclusions}

This study substantially expands the concept of the addressee on YouTube by decoupling the addressee from the message that is responded to and identifying new potential addressee types. It is also the first study (to our knowledge) to demonstrate an interaction between topic and addressee type in comment threads. In the process, we identified differences in what was talked about in comments and replies. Finally, the analysis revealed some ways YouTube users dealt with and talked about COVID-19 in the early days of the pandemic.

A limitation of this study is the representativeness of the data, as only three threads were analyzed. Further, the situation of the threads (COVID-19) is exceptional, although YouTube is often used to discuss crises. Threads discussing a wider range of topics should be analyzed. Also, several categories in our coding schemes were not found in our data. These might occur in research involving more and different kinds of prompts, or the coding scheme might need to be simplified.

The findings of this study have broader implications for research and design. Our coding schemes could be customized to analyze turn relatedness on other prompt-focused platforms such as Facebook, Instagram, and news sites. Further, the associations identified between topic and addressee could facilitate automated topic identification and improved annotations for higher levels of interaction analysis, such as dialogue acts [7] and discussion trees [19], as noted by [20].

Finally, our findings suggest that the YouTube platform should support deep threading to indicate logical turn adjacency at multiple levels of reply. Rich-prompt platforms such as YouTube should also consider implementing a reply mechanism or mechanisms to address common addressee types that occur in prompts (such as speaker and prompt poster). Such changes would facilitate automated thread identification and improve the coherence of user conversations on rich-prompt platforms.

\section{References}

[1] Basch, C. H., Basch, C. E., Ruggles, K. V., \& Hammond, R. (2015). Coverage of the Ebola virus disease epidemic on YouTube. Disaster Medicine and Public Health Preparedness, 9(5), 531-535.

[2] Benson, P. (2015). Commenting to learn: Evidence of language and intercultural learning in comments on YouTube videos. Language Learning \& Technology, 19(3), 88-105.
[3] Bou-Franch, P., Lorenzo-Dus, N., \& Blitvich, P. G. C. (2012). Social interaction in YouTube text-based polylogues: A study of coherence. Journal of Computer-Mediated Communication, 17(4), 501-521.

[4] Cohn, M. A., Mehl, M. R., \& Pennebaker, J. W. (2004). Linguistic indicators of psychological change after September 11, 2001. Psychological Science, 15, 687-693.

[5] Donath, J. (2002). A semantic approach to visualizing conversation. Communications of the ACM, 45.

[6] Dynel, M. (2014). Participation framework underlying YouTube interaction. Journal of Pragmatics, 73, 37-52.

[7] Ferschke, O., Gurevych, I., \& Chebotar, Y. (2012). Behind the article: Recognizing dialog acts in Wikipedia Talk pages. Proceedings of the 13th EACL, 777-786.

[8] Goffman, E. (1959). Presentation of self in everyday life. New York, NY: Doubleday Anchor.

[9] Grice, H. P. (1975) Logic and conversation. In Syntax and semantics: Speech acts (pp. 41-58). Academic Press.

[10] Herring, S. C. (1999). Interactional coherence in CMC. Journal of Computer-Mediated Communication, 4(4).

[11] Herring, S. C. (2003). Dynamic topic analysis of synchronous chat. In New Research for New Media: Innovative Research Methodologies Symposium. Minneapolis, MN: University of Minnesota.

[12] Herring, S. C. (2013). Discourse in Web 2.0: Familiar, reconfigured, and emergent. In D. Tannen \& A. M. Tester (Eds.), Discourse 2.0: Language and new media (pp. 1-25). Washington, DC: Georgetown University Press.

[13] Herring, S. C., \& Kurtz, A. J. (2006). Visualizing Dynamic Topic Analysis. In Proceedings of $\mathrm{CHI}^{\prime} 06$. ACM.

[14] Honeycutt, C., \& Herring, S. C. (2009). Beyond microblogging: Conversation and collaboration via Twitter. Proceedings of the Forty-Second Hawai'i International Conference on System Sciences. Los Alamitos, CA: IEEE.

[15] Jucker, A. H. (2010). Audacious, brilliant!! What a strike! Live text commentaries on the Internet as real-time narratives. In C. R. Hoffmann (Ed.), Narrative revisited: Telling a story in the age of new media (pp. 57-77). Amsterdam: Benjamins. [16] Laaksonen, S. M., Pantti, M., \& Titley, G. (2020). Broadcasting the movement and branding political microcelebrities: Finnish anti-immigration video practices on YouTube. Journal of Communication, 70(2), 171-194.

[17] Lambiase, J. J. (2010). Hanging by a thread: Topic development and death in an online discussion of breaking news.Language@Internet, 7, article 9.

[18] Lange, P. G. (2007). Publicly private and privately public: Social networking on YouTube. Journal of Computer-Mediated Communication, 13(1), 361-380.

[19] Laniado, D., Tasso, R., Volkovich, Y., \& Kaltenbrunner, A. (2011). When the Wikipedians talk: Network and tree structure of Wikipedia discussion pages. ICWSM 2011.

[20] Lüngen, H., \& Herzberg, L. (2019). Types and annotation of reply relations in computer-mediated communication. EuJAL 2019, 7(2), 305-331.

[21] McDaniel, S. E., Olson, G. M., \& Magee, J. C. (1996). Identifying and analyzing multiple threads in computer-mediated and face-to-face conversations. In Proceedings of Computer Supported Cooperative Work '96. ACM.

[22] Miller, E. (2015). Content analysis of select YouTube postings: Comparisons of reactions to the Sandy Hook and 
Aurora shootings and Hurricane Sandy. Cyberpsychology, Behavior, and Social Networking, 18, 11, 635-640.

[23] Mohsin, M. (2020). 10 Youtube Stats Every Marketer Should Know in 2020 [Infographic]. Oberlo. Retrieved from https://www.oberlo.com/blog/youtube-statistics

[24] Perer, A., \& Shneiderman, B. (2005). Beyond threads: Identifying discussions in email archives. In IEEE Symposium on Information Visualization (InfoVis), Minneapolis, MN.

[25] Rohall, S., Gruen, D., Moody, P., \& Kellerman, S. (2001). Email visualizations to aid communications. In IEEE Symposium on Information Visualization (InfoVis), San Diego, CA. [26] Severinson-Eklundh, K. (2010). To quote or not to quote: Setting the context for computer-mediated dialogues. Language@Internet, 7, article 5.

[27] Sinclair, J. M., \& Coulthard, M. (1975). Towards an analysis of discourse. Oxford, UK: Oxford University Press.

[28] Smith, M., Cadiz, J., \& Burkhalter, B. (2000). Conversation trees and threaded chats. In Proceedings of CSCW 2000, 97-105. ACM.

[29] Towner, T. L., \& Dulio, D. A. (2011). An experiment of campaign effects during the YouTube election. New Media \& Society, 13(4), 626-644.

[30] Venolia, G., \& Neustaedter, C. (2002). Understanding sequence and reply relationships within email conversations: A mixed-model visualization. Proceedings of CHI 2003.

[31] Werry, C. C. (1996). Linguistic and interactional features of Internet Relay Chat. In S. Herring (Ed.), Computer-mediated communication (pp. 47-63). Amsterdam: Benjamins.

\section{Appendix}

\section{Table A. Addressee Codes*}

\begin{tabular}{|c|l|}
\hline Code & Description \\
\hline A1 & Producer of the matrix video \\
\hline A2-1 & Speaker in the matrix video \\
\hline A2-2 & Non-speaking participant in the matrix video \\
\hline A3 & Producer of the first-level embedded video \\
\hline A3-1 & Speaker in the first-level embedded video \\
\hline A3-2 & $\begin{array}{l}\text { Non-speaking participant in the first-level } \\
\text { embedded video }\end{array}$ \\
\hline A4 & $\begin{array}{l}\text { (This code would be used if there was more than } \\
\text { one level of embedded video) }\end{array}$ \\
\hline A5 & Redistributor \\
\hline A6 & $\begin{array}{l}\text { Previous commenter or previous user who clicked } \\
\text { like/dislike }\end{array}$ \\
\hline A7 & YouTube platform \\
\hline A8 & $\begin{array}{l}\text { General audience (Default; not individually } \\
\text { addressed) }\end{array}$ \\
\hline A9 & Uncodeable: unclear or ambiguous \\
\hline
\end{tabular}

\section{*Addressee code examples}

A1: "Thanks for keeping the show alive!" (Colbert)

A2-1: "God Bless You Chris!!!" (Cuomo)

A6: “@xxxxx I think it is a bit overstated.” (Black)

A8: "Steven's slowly going insane" (Colbert)

A9: "Hello" (Colbert)
Table B. Topic Codes**

\begin{tabular}{|c|l|}
\hline Code & \multicolumn{1}{|c|}{ Description } \\
\hline T1-1 & Situation of the matrix video \\
\hline T1-2 & Situation of the embedded video \\
\hline T2-1 & Setting of the matrix video \\
\hline T2-2 & Setting of the embedded video \\
\hline T3-1 & Speaker's content in the matrix video \\
\hline T3-2 & Speaker's content in the embedded video \\
\hline T4-1 & Matrix video producer's message \\
\hline T4-2 & Embedded video producer's message \\
\hline T5-0 & Previous comment or previous content \\
\hline T5-1 & Matrix video \\
\hline T5-2 & Embedded video \\
\hline T6-1 & Producer of the matrix video \\
\hline T6-2-1 & Speaker in the matrix video \\
\hline T6-2-2 & Non-speaking participant in the matrix video \\
\hline T6-3 & Producer of the first-level embedded video \\
\hline T6-3-1 & Speaker in the first-level embedded video \\
\hline T6-3-2 & $\begin{array}{l}\text { Non-speaking participant in the first-level embed- } \\
\text { ded video }\end{array}$ \\
\hline T6-4 & $\begin{array}{l}\text { (This code would be used if there was more than } \\
\text { one level of embedded video) }\end{array}$ \\
\hline T6-5 & Redistributor \\
\hline T6-6 & Previous commenters \\
\hline T7-1 & Matrix show (including its technical quality) \\
\hline T7-2 & YouTube platform \\
\hline T7-3 & Previous self-comment or self-proposition \\
\hline T7-4 & Formulaic greetings/well wishes \\
\hline T7-5 & Uncodeable: unclear or ambiguous \\
\hline T7-6 & $\begin{array}{l}\text { Other: referent is clear but there is no other code } \\
\text { for it, e.g., religious remarks }\end{array}$ \\
\hline
\end{tabular}

\section{**Topic code examples}

T1-1: "we're not testing healthcare workers who are doing 12 hours at a time" [referring to COVID-19] (Colbert)

T1-2: "people could've stopped her from doing that" [referring to a case of hoarding] (Black)

T2-1: "Nice bathroom!" (Colbert)

T3-1: "Chris called his brother "capitain [sic] banana", (Cuomo)

T5-0: "@xxxxx I agree. Trump is horrible but he can also be funny. " (Black)

T5-1: "hilarious..... and well written..." (Colbert)

T6-2-1: "Steven's slowly going insane" (Colbert)

T6-3-1: "This woman is an analog for the entirety of capitalists" (Black)

T6-6: "@xxxxx u r name says it dummy" (Cuomo)

T7-1: "The video dimension is a bit off." (Colbert)

T7-4: "Get well soon" (Cuomo)

T7-5: "This is weird" [could be referring to setting or video] (Colbert) 